\title{
CLASSIFICAÇÃO ESTRUTURAL E TECTÔNICA DOS GRANITÓIDES NEOPROTEROZÓICOS DO CINTURÃO PARAÍBA DO SUL NO ESTADO DO RIO DE JANEIRO
}

\author{
R.Machado ${ }^{1}$ \& M.Demange ${ }^{2}$
}

PALAVRAS-CHAVE: granitóides neoproterozóicos, classificação tectônica, tipo de magmatismo.

MACHADO, R; DEMANGE, M. (1994) Classificação estrutural e tectônica dos granitóides neoproterozóicos do Cinturão Paraiba do Sul no Estado do Rio de Janeiro. Bol.JG-USP, Sér.Cient., 25:81-96.

\section{RESUMO}

Os granitóides Neoproterozóicos do cinturāo Paraiba do Sul no Estado do Rio de Janeiro săo classificados, neste trabalho, em função das fases tectônicas regionais, dos domínios estruturais de ocorrência, do nível crustal de colocaçẩo, do tipo composicional, do caráter tectônico e de seu posicionamento temporal com base nos dados geocronológicos disponiveis, muitos deles ainda inéditos.

São distinguidos três grupos de granitóides: $\sin -\mathrm{F}_{2}, \sin -\mathrm{F}_{3}$ e $\sin -\mathrm{F}_{4}$. Os sin- $\mathrm{F}_{2}$ dividem-se em dois subgrupos. Um deles, predominante, de composição expandida (tonalito/granodionito/granito), com idade ao redor de $620 \mathrm{Ma}$, comparável aos granitos tipo-I Cordilheirano, é colocado em nível crustal de fácies anfibolito a granulito. A origem deste magmatismo é relacionada a uma zona de subdução, com mergulho de SE para NW, por debaixo do cinturäo Paraiba do Sul. O outro subgrupo, subordinado, é constituído por granitóides migmatiticos do tipo-S, atribuidos a um evento colisional com idade ao redor de $600 \mathrm{Ma}$. Os granitóides sin- $\mathrm{F}_{3}$ e sin- $\mathrm{F}_{4}$, de composiçâo não expandida (com predominio de sieno e monzogranitos), ş̊o considerados como magmatismo tipo-I Caledoniano, de caráter tardia pós-colisional, com idade entre 490 e $560 \mathrm{Ma}$.

\section{ABSTRACT}

The granitoids of the Neoproterozoic in the Paraiba do Sul belt in the State of Rio de Janeiro are classified according to their ages related to the recognized tectonic phases, their location in the different tectonic domains, the crustal level of emplacement, petrografic compositions and the tectonic environment. Three groups of granites are distinguished: $S y n-F_{2}, S y n-F_{3}$ and $S y n-F_{4}$. The compositionally expanded syn-F 2 granitoids, (e.g. tonalite/granodiorite/granite), with age about the $620 \mathrm{Ma}$, are comparable to the Cordilleran I-Type magmatism, emplaced at level of the crust from amphibolite/granulite facies, and their origin is related to a subduction zone below of the Paraiba of Sul belt, from SE to NW. The other syn- $\mathrm{F}_{2}$ are migmatitic S-type granitoids, linked to a continental collision event with age about the $600 \mathrm{Ma}$. The syn- $\mathrm{F}_{3}$ and syn- $\mathrm{F}_{4}$ groups are compositionally restricted (e.g. monzogranite and syenogranite dominantly) $(-490-560 \mathrm{Ma})$, and their magmatism is considered to be Caledonian I-Type.

\footnotetext{
'Departamento de Geologia Geral, Instituto de Geociências/USP, São Paulo, Brasil. Bolsista do CNPq.

${ }^{2}$ Centre d'Informatique Geologique, Ecole des Mines de Paris, Fontainebleau, França.
} 


\section{INTRODUÇÃO}

As rochas granitóides do Estado do Rio de Janeiro são classificadas em função das fases tectônicas regionais, das associações petrográficas, do nivel crustal de colocação, da relação com o metamorfismo regional e com os dominios estruturais de ocorrência. Finalmente, os granitos são classificados em função das condições tectônicas de formação, levando-se em consideração os aspectos petrográficos/composicionais, litogeoquímicos e geocronológicos disponiveis na literatura ou, ainda, como dados inéditos

O magmatismo granítico aqui estudado é dividido em três grupos de maciços (do mais antigo para o mais novo): os $\sin -\mathrm{F}_{2}$, os sin- $\mathrm{F}_{3}$ e os $\sin -\mathrm{F}_{4}$. Os maciços $\sin -\mathrm{F}_{2}$ são foliados, na forma de grandes batólitos lineares, dominando composição granodiorítica a tonalítica e colocação em fácies anfibolito a granulito. Os maciços $\sin -\mathrm{F}_{3}$ são representados por corpos menores, muitas vezes foliados, alongados, dominando composiçăo monzo a sienogranítica, com colocação de fácies anfibolito a xisto-verde alto, sendo associados às zonas de cisalhamento dúcteis de alto ângulo. Os maciços sin- $\mathrm{F}_{4}$, cacterizados por corpos mais homogêneos, na forma de slocks, subarredondados, não deformados, com composição monzogranítica a álcali-feldspato granitica, de colocação mais rasa do que os anteriores. O posicionamento desses maciços é independente da estruturaçăo regional NE-SW. De maneira geral, este último grupo corresponde ao magmatismo descrito na literatura como tardi- a pós-tectônico.

Os granitos sin- $\mathrm{F}_{2}$ representam um magmatismo de composição expandida, comparável ao dos granitos tipo-I Cordilheirano da classificação de Pitcher (1979, 1982). Entretanto, os granitos $\sin -\mathrm{F}_{3}$ e $\sin -\mathrm{F}_{4}$ correspondem a um magmatismo de composição mais restri- ta, sendo mais próximos dos granitos tipo-I Caledoniano segundo a classificação deste mesmo autor.

\section{TRABALHOS ANTERIORES}

A maior soma de dados sobre as rochas graníticas do Estado do Rio de Janeiro diz respeito à região serrana deste Estado e aos arredores da cidade do Rio de Janeiro. Os trabalhos referem-se essencialmente a maciços graníticos de características tardi- a postectônicas. Neles estão contidas informaçōes geológicas, petrográficas, geoquímicas e geocronológicas.

Destacam-se os trabalhos de Leonardos Jr. (1973), Pires et al. (1982), Penha (1984), Penha et al. (1980), Penha \& Wiedemann (1984), Junho (1982, 1991, 1993), Junho \& Penha (1985), Junho et al. (1987), Caddah et al. (1987) e Porto Jr. et al. (1992) sobre os granitos dos arredores da cidade do Rio de Janeiro e das regiōes de Petrópolis e Teresópolis; Puget \& Penha (1980) e Zorita \& Penha (1980) sobre os granitos da região de Magé (granitos Suruí e Andorinha); Machado Filho et al. (1983), Barbosa \& Sad (1985), Machado (1990) e Machado \& Demange (1992) sobre o batólito Serra dos Orgãos; Hippertt (1990) sobre o maciço Niterói; Batista (1984), Rêgo (1989) e Rêgo \& Figueiredo (1991, 1994) sobre os maciços Bela Joana e Angelim.

Os trabalhos de cunho regional, que buscam a integração e correlação entre os diferentes tipos de maciços, a nivel do Estado, são relativamente escassos, restringindo-se aos trabalhos de Machado Filho et al. (1983), Wiedemann et al. (1987), Machado \& Peloggia (1987), Machado et al. (1989) e Machado \& Demange (1992).

Assinalam-se alguns trabalhos de correlação regional de granitos tardi- a 
pós-tectônicos entre os Estados do Espirito Santo (Santa Angélica, Castelo, Venda Nova, Conceição de Muqui, Mimoso do Sul e Alfredo Chaves) e Rio de Janeiro (Pedra Branca, Nova Friburgo e Frades), como os de Wiedemann et al. (1986, 1987), Bayer et al. (1986) e Horn \& Weber-Diefenbach (1987).

As informações geocronológicas existentes sobre os maciços graníticos do Rio de Janeiro apontam idades brasilianas. Os principais dados estão contidos nos trabalhos de Cordani et al. $(1968,1973)$, Delhal et al. (1969), Bigazzi et al. (1971), Cordani \& Teixeira (1979), Siga Jr. et al. (1982), Fonseca (1979), Fonseca et al. (1984), Batista (1984), Batista \& Kawashita (1985) e Menezes et al. (1987).

Trabalhos recentes, realizados no Estado do Espirito Santo e no norte do Estado do Rio de Janeiro, têm reconhecido a existência de magmatismo cálcioalcalino e álcali-cálcico relacionado a um arco magmático brasiliano, que teria se desenvolvido no intervalo de $590-480$ Ma, para o qual é proposta a denominação de "arco magmático Rio Doce" (Figueiredo \& Campos Neto, 1993). Este mesmo arco também é postulado para a região por Wiedemann (1993), porém com intervalo mais amplo, entre 580 e $450 \mathrm{Ma}$. Esta última autora reconhece para este magmatismo, no Estado do Espirito Santo, três séries magmáticas: uma toleitica, uma cálcio-alcalina médio a alto-K e outra calci-alcalina/álcali-cálcica de alto-K.

\section{O CINTURÃo PARAÍBA DO SUL NO ESTADO DO RIO DE JANEIRO}

O segmento do Cinturão Paraiba do Sul, no Estado do Rio de Janeiro e na extremidade sul de Minas Gerais, pode ser dividido em vários domínios estruturais, que diferem principalmente pelo nivel estrutural exposto. Esta região faz parte do Cinturão de Cisalha- mento Atlântico (Machado \& Endo, 1993) e da microplaca Serra do Mar (Figueiredo \& Campos Neto, 1993).

Este cinturão, no Estado do Rio de Janeiro, organiza-se em quatro domínios estruturais maiores, dispostos, de NW para SE, na seguinte ordem: (1) Dominio Juiz de Fora, (2) Dominio Paraíba (Norte e Sul), (3) Domínio Serra dos Orgãos e (4) Domínio Litorâneo (Norte e Sul) (Fig. 1).

O domínio Juiz de Fora é formado por rochas metamórficas de alto grau, com amplo desenvolvimento de fácies granulito. Nele, distinguem-se três unidades: uma plutônica, com rochas charnockíticas (unidade Comendador Venâncio), e duas outras essencialmente metassedimentares. Destas, uma é formada por gnaisses quartzo-feldspáticos (unidade Itaperuna) e outra por gnaisses granadiferos (unidade Raposo), incluindo ainda gnaisses miloníticos e blastomiloníticos (Barbosa \& Sad, 1983a, b, c).

O dominio Paraíba é subdividido por uma zona de cisalhamento em domínio Paraiba Norte (fácies anfibolito, a SW, e granulito, a NE) e domínio Paraíba Sul. Naquele, afloram mais extensivamente rochas do embasamento - unidades Quirino (Machado, 1984) e São João do Paraíso (Gomes \& Batista, 1978), e neste predominam rochas metassedimentares, as quais, nos trabalhos de mapeamento geológico realizados no Estado do Rio de Janeiro pela GEOSOL, foram englobadas na unidade Itaocara (Castro et al., 1984a, b; Sad \& Barbosa, 1988).

No domínio Serra dos Órgãos, em fácies anfibolito inferior, ocorrem ortognaisses intrusivos em metagrauvacas homogêneas que foram incluidos nas unidades Bingen e Santo Aleixo (Penha et al., 1979), Rio Negro (Matos et al., 1980) e Japeri (Machado, 1984), informalmente reunidos numa unidade de gnaisses granitóides (Machado \& Peloggia, 1987). 


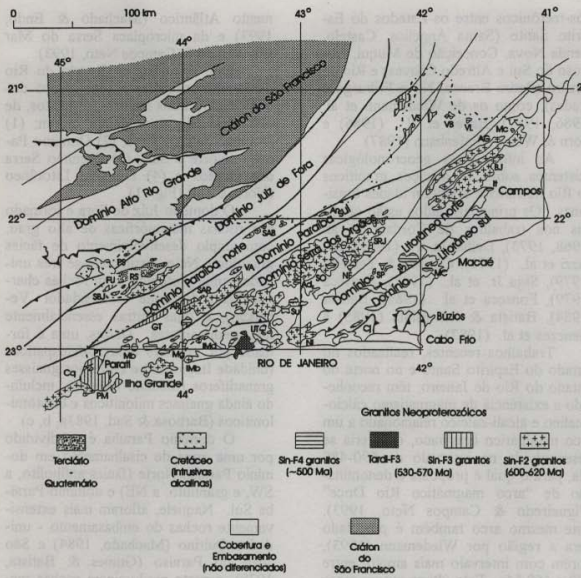

Figura 1 - Mapa de Distribuiçăo e de Classificaçăo Tectônica dos granitóides Neoproterozóicos do Estado do Rio de Janeiro (Adaptado de Machado \& Peloggia, 1987). Granitóides Sin-F2: SO - Serra dos Órgãos; RT (Rio Turvo); AG - Angelim; BJ - Bela Joana; NI - Niterói; IMB - Illa da Marambaia; IMD - Iha da Madeira; IG - Tha Grande; SAR - Serra das Araras, SAB - Serra das Abobboras; Granitos Sin-F 3 : GT- Getulândia; AR - Arrozal; VA - Vassouras; VS - Varre Sai; An - Anta; PT - Parati; PM - Parati-Mirim. Granitos Tardi-F3: PB - Pedra Branca. Granitos Sin-F4: SN - Sana; SP - Săo Pedro; MC - Macaé; IT - Itaoca; MC - Morro do Côco; CJ - Cajú; VL - Valăo da Laje; VB - Valăo do Bambui; SJR- São José do Ribeirão; NF - Nova Friburgo; FR - Frades; AD - Andorinhas; SU - Suruí; UT- Utinga; MG - Mangaratiba; MB - Mambucaba; CR - Carrasquinho; RS - Resende; FU - Funil; PS - Pedra Selada; SJB - Sảo José do Barreiro.

No domínio Litorâneo, reconhecem-se dois subdomínios: um, situado em fácies anfibolito inferior/granulito, a Norte, e outro, a Sul, em grau metamórfico mais baixo, mas ainda em fácies anfibolito, com as rochas supracrustais mostrando decréscimo de metamorfismo de NW para SE (Machado \& Demange, 1990).

No subdomínio Litorâneo norte, 
com exposição de rochas infracrustais, podem ser distinguidas duas unidades maiores: uma inferior, unidade São Fidélis, e outra superior, unidade Santo Eduardo (equivalente da unidade Itaocara do domínio Paraiba).

A unidade inferior, em fácies anfibolito inferior/granulito, é constituida por gnaisses ricos em granada e biotita, intensamente migmatizados, contendo expressivos pacotes de gnaisses kinzigiticos e intercalações de rochas cálciosilicáticas.

A unidade superior, em fácies anfibolito mais baixo, composta pelas unidades Santo Eduardo e Itaocara - introduzidas pela GEOSOL (Sad et al., 1980; Castro et al., 1984a, b; Sad \& Dutra, 1988), constitui-se de biotita-gnaisses (derivados de sedimentos psamo-pelíticos), (hornblenda)-biotita-gnaisses, gnaisses cálcio-silicáticos (sedimentos psamo-pelíticos-carbonáticos) e expressivos pacotes de metacalcáreos, metamargas e quartzitos.

Rochas do embasamento (ortognaisses tonalíticos/granodioriticos) são reconhecidas nos diferentes dominios estruturais acima descritos. Contudo, tais rochas têm sido confundidas com os granitos $\sin -\mathbf{F}_{2}$. Dentre elas, são aqui consideradas como embasamento as unidades Bingen, Santo Aleixo, Rio Negro, São João do Paraíso, Quirino e Araruama, com esta última possuindo idade transamazônica, confirmada por vários autores (Delhal et al., 1969; Zimbres et al., 1990; Fonseca, 1994).

Os domínios acima discutidos, acham-se delimitados por importantes zonas de cisalhamento dúcteis de alto ângulo, de direção NE-SW. A implantação destas estruturas, ao contrário do que tem sido postulado pela maioria dos autores, parece ter ocorrido já na fase precoce de evolução da orogênese brasiliana no cinturão (Machado \& Endo, 1993).

Estas zonas de cisalhamento foram acompanhadas pelo desenvolvimento de milonitos de alta temperatura, sendo comum tramas com superposição cinemática. A movimentação principal dessas estruturas parece estar relacionada à fase de deformação $F_{3}$, com idade situada em torno de $550 \mathrm{Ma}$, enquanto a atividade mais antiga, relacionada à fase $\mathrm{F}_{2}$, situa-se ao redor de 600 a $620 \mathrm{Ma}$ (R.Machado, dados inéditos).

Os maciços sin- $\mathrm{F}_{3}$, principalmente no domínio Paraiba Sul, possuem forma alongada e são controlados inteiramente por estas estruturas. Observam-se, neles, texturas magmáticas ao lado de estruturas deformacionais, com feições assimétricas indicativas de deformação não-coaxial.

\section{Fases tectônicas regionais}

De uma forma genérica, a história deformacional desses dominios pode ser agrupada em quatro fases tectônicas regionais que, da mais antiga para mais nova, são designadas de $F_{1}, F_{2}, F_{3} \in F_{4}$, e apresentam diferentes caracteristicas.

A fase $F_{1}$ responde pela formação de um bandamento deformacional, tendo sido acompanhada por intenso metamorfismo e migmatização. As dobras desta fase são raras e, quando presentes, são do tipo isoclinal, restringindo-se praticamente a núcleos do embasamento. Nas rochas supra e infracrustais, ou estas estruturas foram integralmente transpostas pela fase $\mathrm{F}_{2}$ ou elas não tiveram desenvolvimento regional. Como estas estruturas foram desenvolvidas em condições metamórficas e nível estrutural similares aos das estruturas $F_{2}$, a distinção entre elas é muito dificil. Além disso, a superposição geométrica das estruturas parece ter ocorrido no mesmo campo de regime de esforços. Deste modo, a distinção entre essas fases parece ter mais um significado geométrico do que genético propriamente dito.

$A$ fase $F_{2}$ aparece como o evento de deformação principal, sendo respon- 
sável pela geração da foliação regional sin-metamórfica e sin-migmática - e pela intensa transposição das estruturas anteriores. Esta foliação é plano axial às dobras de charneiras espessadas e flancos adelgaçados, com perfis cerrados a isoclinais. A esta fase associam-se, a nivel regional, zonas de cisalhamento dúcteis de baixo e alto ângulos, as quais imprimiram um forte caráter milonítico e blastomilonítico às rochas do domínio Juiz de Fora, assim como a certos núcleos do embasamento do domínio $\mathrm{Pa}$ raiba.

A fase $\mathrm{F}_{3}$ é posterior à foliação regional, tendo gerado dobras em diferentes escalas, em geral com perfis entre abertos a fechados, sendo comuns eixos subhorizontalizados. Esta fase foi responsável pela estruturação das grandes dobras regionais, com valor de sinclinório (domínio Paraiba) ou de anticlinório (domínio Serra dos Órgãos), e também pela implantação e reativação de zonas de cisalhamento de alto ângulo, cuja idade é posicionada ao redor de $550 \mathrm{Ma}$. (Machado \& Demange, 1991). Estas zonas de cisalhamento são mais expressivas no dominio Paraiba Sul, onde possuem largura entre 25 a $30 \mathrm{~km}$ (Machado, 1983). Aqui, elas desempenharam importante papel no controle, ascensão e colocação dos maciços graníticos $\sin -\mathrm{F}_{3}$.

A fase $F_{4}$, de direção transversal à orientação geral do cinturão (NW-SE a WNW-SSE e NNW-SSE), mostra-se descontinua e é responsável por estruturas de importância secundária. A esta fase associam-se dobras suaves e abertas e também zonas de cisalhamento rúpteis e rúpteis/dúcteis, menos expressivas do que as anteriores.

\section{Granitóides Sin-F}

Os granitóides relacionados à esta fase são, em geral, foliados, com a foliação sendo muito intensa nas bordas dos maciços, onde podem apresentar, muitas vezes, estruturas gnáissica e milonitica. $\mathrm{Na}$ sua parte central, passam a predominar estruturas mais isótropas. Em direção às bordas, ocorrem enclaves com estruturas correlatas à foliação regional das rochas encaixantes $\left(\mathrm{S}_{\mathrm{n}+1}\right)$. Como estas estruturas são atribuidas à fase $\mathrm{F}_{2}$ (Machado \& Demange, 1992), concluise, portanto, que a colocação destes corpos ocorreu durante esta fase. A idade atribuida a esta fase é ao redor de $600 \mathrm{Ma}$ (Machado \& Demange, 1991).

Os granitóides sin- $\mathrm{F}_{2}$, em função do nivel metamórfico de colocação, podem ser divididos em quatro grupos: 1) em fácies granulito; 2) transição făcies granulito/anfibolito; 3) em fácies anfibolito inferior e, 4) em fácies anfibolito superior.

O primeiro grupo está representado por charnockitos em maciços subconcordantes, cujo principal representante é o maciço Bela Joana. Estes maciços mostram associações diferenciadas, com termos enderbíticos e charnockíticos dominantes. É notável seu enriquecimento em granada, sobretudo na bordas do maciço. Este fato se deve mais provavelmente a uma contaminação pelos paragnaisses encaixantes (unidades São Fidélis e Ernesto Machado) do que a uma origem primária, conforme atribuido por Rêgo (1989). Os dados radiométricos disponiveis para - maciço Bela Joana apontam idades $\mathrm{Rb} / \mathrm{Sr}$ de $599,6 \pm 10,2 \mathrm{Ma}$, com razão inicial de 0,708 (Batista, 1984). Os maciços charnockíticos ocorrem em domínios com exposição de rochas em fácies granulito: domínios Juiz de Fora, Paraiba Norte, Litorâneo Norte e, provavelmente, na porção inferior do dominio Serra dos Orgãos.

O segundo grupo, caracterizado pela ocorrência de rochas charnockiticas e graniticas associadas, reflete condiçōes metamórficas de colocação compativeis com a transição fácies granulito/anfibolito. O principal representante deste 
grupo é o maciço Niterói. Neste maciço, predominam rochas de granulação grossa, porfiríticas, de composição entre granodioritica a monzogranítica, onde são comuns megacristais de feldspato de potássio entre 10 e $15 \mathrm{~cm}$. Distinguemse duas faciologias principais, uma de charnockitos esverdeados e outra de granitos rosados. São rochas foliadas, texturalmente muito similares. O contato entre elas é em geral sinuoso, sendo comum a presença de enclaves microgranulares de composição quartzo diorítica e tonalítica. Estas duas faciologias são cortadas por veios subconcordantes, foliados, constituídos por granitos hololeucocráticos e pegmatitos com granada.

O terceiro grupo, em fácies anfibolito inferior, é representado por maciços subconcordantes, encaixados em metassedimentos da unidade São Fidélis, cujo representante principal é o batólito Angelim. A parte inferior destes maciços mostra, freqüentemente, aspecto migmatítico, com texturas orientadas, ricas em enclaves e estruturas tipo schlierens, enquanto a parte superior é mais homogênea. Apresenta uma associação diorito-tonalito-granodiorito-granito, juntamente com granito hololeucocrático com granada. É caracterizado como um magmatismo de afinidade cálcio-alcalina, enriquecido em elementos incompatíveis, principalmente $\mathrm{Rb}$ e TR totais, de profundidade relativamente mais rasa do que o Bela Joana, com a sua geração sendo também relacionada à subducção de crosta oceânica (Rêgo, 1989). Os dados geocronológicos, $\mathrm{Rb} / \mathrm{Sr}$, existentes sobre este maciço, apontam idades de $731,9 \pm 28,6 \mathrm{Ma}$ e $502,6 \pm 133,6 \mathrm{Ma}$, com razões iniciais de 0,708 e 0,709 , respectivamente (Batista, 1984; Batista \& Kawashita, 1985).

Outros maciços, de aspecto migmatítico, colocados na porção inferior da fácies anfibolito, como Serra das Araras e Rio Turvo, designados de leucogranitos aluminosos por Machado et al. (1989), são nitidamente granitos do tipo-S, oriundos da fusão parcial de metassedimentos, relacionados a um regime colisional (Machado \& Demange, 1991). Esses maciços são encontrados nos dominios Juiz de Fora (Rio Turvo), Paraiba Sul (Serra das Araras) e Litorâneo Norte (Angelim) (Fig. 1).

O quarto e último grupo, em fácies anfibolito superior, representado pelo batólito Serra dos Órgãos, o mais expressivo batólito granítico da região estudada, posiciona-se entre os gnaisses das unidades Bingen e Santo Aleixo. É um batólito linear comparável aos batólitos tipo Cordilheirano. Possui forma estratóide, com cerca de $165 \mathrm{~km}$ de extensão, foliado, concordante com a estrutura regional, sendo deformado pelas fases $\mathrm{F}_{3}$ e $\mathrm{F}_{4}$ (Machado \& Demange, 1994). Seus tipos petrográficos são muito homogêneos, podendo-se distinguir duas faciologias principais: uma, de granodioritos leucocráticos, com termos subordinados de tonalitos e quartzodioritos, com biotita-anfibólio (hastingsita) e apatita-zircão-titanita; e outra, de monzogranitos, com proporções menores de granitos (leuco a hololeucocráticos), com biotita, zircão-apatitaallanita $\mathrm{e}$, mais raramente, granada $\mathrm{e}$ anfibólio. Os dados geoquímicos apontam para um magmatismo cálcio-alcalino com caracteristicas toleíticas, cuja diferença principal dos batólitos cordilheiranos, tipo Sierra Nevada, é um enriquecimento substancial em $\mathrm{Fe}_{2} \mathrm{O}_{3}$ em todos os tipos composicionais (Machado \& Demange, 1994).

\section{Granitos Sin- $\mathbf{F}_{3}$}

Estes granitos apresentam maior desenvolvimento no dominio Paraíba (Norte e Sul), sendo encontrados também no segmento meridional do domínio Juiz de Fora (Fig. 1). Naquele domínio, ao longo da zona de cisalhamento de Além-Paraiba, ocorrem inúmeros corpos graniticos não inteiramente registrados 
nos trabalhos de cartografia geológica realizados no Estado do Rio de Janeiro, na escala 1:50.000, no âmbito do Projeto de Cartografia Geológica. A intensa deformação imposta a esses corpos pela atividade desta zona de cisalhamento, imprimindo-lhes uma forte estrutura gnáissica e milonítica, tem levado vários autores a considerá-los como integrantes dos gnaisses regionais.

No mapa da Figura 1 são assinalados os maciços foliados contemporâneos à fase $\mathrm{F}_{3}$, como os granitos de Vassouras, Getulândia, Arrozal, Resende, Varre-Sai, Parati, dentre outros. São macicos alongados, foliados, com presença de uma foliação de fluxo magmático, muitas vezes afetada por um foliação milonitica subparalela, de alto ângulo. Predominam rochas de granulação média a grossa, inequigranulares e porfiriticas, leucocráticas, rosadas e esbranquiçadas, podendo conter enclaves microgranulares básicos de extensão quilométrica, a exemplo do que ocorre no maciço Getulândia. São granitos com biotita, incluindo às vezes também anfibólio (Parati e Varre-Sai), quartzo, microclinio e plagioclásio (oligoclásio/andesina), com titanita, zircão, apatita, granada e magnetita como acessórios (Reis et al., 1982b; Machado, 1984; Sperling et al., 1983; Castro et al, 1984b). A composição dominante é monzogranítica. Localmente, como na região de Passa Três, registram-se também granitos com muscovita, granada e turmalina, muito ricos em quartzo, numa associação tipicamente de granitos do tipo-S, no sentido de Chappell \& White (1974).

O posicionamento dos granitos $\sin -\mathrm{F}_{3}$ acha-se intimamente relacionado com a atividade principal das zonas de cisalhamento de Além-Paraíba, podendo sua colocação ser explicada pela variação do regime deformacional ao longo desta estrutura (transtração $\mathrm{x}$ transpressão) ou pela mudança cinemática ocorrida durante a sua história deformacio- nal, conforme proposto por Machado \& Endo (1994). Granitóides sin-tectônicos, relacionado a zonas de cisalhamento dúctil em regime transpressional, são descritos na região de Arrozal/Barra Mansa (Nummer et al., 1995).

\section{Granitos Sin-F}

Os granitos $\sin -\mathrm{F}_{4}$ apresentam maior incidência nos domínios Litorâneo, Serra dos Órgãos, e na extremidade Sul do domínio Paraiba (Fig. 1). São os tipos de maciços mais numerosos no Estado do Rio de Janeiro, ocorrendo sempre em corpos circunscritos. Muitos deles, não são mais controlados pelas estruturas NE do cinturão, passando a ter influência de estruturas E-W e NWSE. Estes maciços possuem diâmetro variável desde poucos $\mathrm{km}$ até, no máximo, $20 \mathrm{~km}$, em média $10 \mathrm{~km}$ (Fig. 1). Alguns desses maciços, como o da Pedra Branca, aqui incluidos no grupo dos $\sin -\mathrm{F}_{4}$, correspondem, na realidade, a maciços tardi- $\mathrm{F}_{3}$.

Estruturalmente, pode-se reconhecer dois grupos de maciços: os homogêneos, de composição geral entre sieno a monzogranítica, tipo Sana e Nova Friburgo, e os maciços zonados, muitas vezes com zoneamento inverso, centrípeto, com composição granodiorítica no centro e granitica nas bordas (Penha, 1984; Penha \& Wiedemann, 1984; Junho, 1991). Este último grupo é mais raro no Rio de Janeiro e tem sido assinalado, por enquanto, apenas no maciço Pedra Branca. Inúmeros exemplos de plutons zonados têm sido descritos no Estado do Espírito Santo, como os maciços Santa Angélica, Castelo, Venda Nova e Jacutinga (Bayer et al., 1986; Wiedemann et al., 1986, 1987).

São também registrados granitos com muscovita, que podem conter granada. Ocorrem, em geral, como pequenos maciços ou mesmo em diques e soleiras, associados muitas vezes a maciços maiores. São rochas leuco a holo- 
leucocráticas, de granulação fina a grossa, muito grossa e pegmatítica, contendo sistematicamente como acessórios allanita, seguida de zircão, apatita, magnetita, pirita e, por vezes, também titanita. Englobam as faciologias descritas nos arredores da cidade do Rio de Janeiro como granitos do tipo Favela e Utinga (Pires et al., 1982; Chaves \& Pires, 1986; Caddah et al., 1987; Valente et al., 1991); ou ainda tipo Andorinha (Penha et al., 1980) e Suruí nas regiōes de Magé (Puget \& Penha, 1980; Zorita \& Penha, 1980), Macaé (Reis et al., 1982a) e Morro do Côco (Fonseca et al., 1979).

\section{DISCUSSÃO E CLASSIFICAC̣ÃO}

Os granitóides do Estado do Rio de Janeiro são aqui classsificados inicialmente com base nas fases de deformações regionais, nas associações petrográfica e composicional, nas condições metamórficas de colocação, juntamente com seu enquadramento nas classificações já consagradas na literatura, como as de Pitcher $(1979,1982)$, Chappell \& White $(1974,1984)$ e Didier et al. (1982).

A relação estrutural das rochas graníticas estudadas com os eventos tectônicos regionais do brasiliano, reconhecidos no Cinturão Ribeira no Estado do Rio de Janeiro, permite separar três grupos principais de maciços graníticos: os maciços sin- $\mathrm{F}_{2}$, foliados, alojados durante o metamorfismo e a deformação regional; os maciços contemporâneos às zonas de cisalhamento dúcteis de alto ângulo (ou sin-transcorrências regionais), tipo Além-Paraiba, os sin- $F_{3} \mathrm{e}$, os maciços posteriores, os $\sin -\mathrm{F}_{4}$, que cortam estas estruturas.

A distribuição e a organização estrutural dos granitóides sin- $\mathrm{F}_{2}$ e sin- $\mathrm{F}_{3}$, na região, acham-se intimamente relacionadas com a estruturação tectônica dos diferentes domínios estruturais aí reco- nhecidos. Contrariamente, os granitos $\sin -\mathrm{F}_{4}$ apresentam uma distribuição independente da estruturação desses domínios, tendo maior incidência nos arredores da cidade do Rio de Janeiro (Fig. 1). Nota-se, porém, que há um maior desenvolvimento dos granitóides sin- $\mathrm{F}_{2}$ nos domínios Serra dos Órgãos e Litorâneo Norte, enquanto os granitóides sin- $\mathrm{F}_{3}$ concentram-se principalmente no domínio Paraiba (Norte e Sul) (Fig. 1). Além disso, os maciços granitóides expressivos do tipo-S, até então conhecidos na região estudada (batólitos Serra das Araras e Rio Turvo), e classificados como sin- $\mathrm{F}_{2}$, são registrados apenas na extremidade Sul dos domínios Paraíba e Juiz de Fora. Cabe, ainda, salientar a existência de uma faixa de ocorrência de rochas charnockíticas ao longo de todo o domínio Litorâneo Norte, adentrando para Sul no Estado de São Paulo e, para Norte, no Estado do Espírito Santo.

A colocação dos granitóides, sin$F_{2}$, ocorreu em nivel crustal de fácies granulito (batólito Bela Joana), na transição granulito-anfibolito (batólito Niterói) e em condições de fácies anfibolito (batólitos Angelim, Serra dos Órgãos, Serra das Abóboras, Serra das Araras e do Rio Turvo). Utilizando-se a classificação de Buddington (1959), os maciços sin- $\mathrm{F}_{2}$ podem ser classificados como plutons catazonais, os sin- $\mathrm{F}_{3}$ como mesozonais, e os $\mathrm{Sin}-\mathrm{F}_{4}$ como epizonais.

Os três grupos de granitos apresentam enclaves microgranulares, sendo porém mais frequuentes nos granitos sin$\mathbf{F}_{2}$. No grupo de granitos $\sin -\mathrm{F}_{3}$, tais enclaves sã̃o em geral mais raros.

A maior parte dos maciços graniticos estudados pertence aos granitos tipo-I da classificação de Chappell \& White $(1974,1982)$, com exceção dos batólitos Serra das Araras e do Rio Turvo que se enquadram nos granitos tipo$\mathrm{S}$ destes autores, ou ainda no tipo Hercínico, de Pitcher (1979). A presença da associação muscovita-biotita em alguns 
maciços $\operatorname{Sin}-\mathrm{F}_{4}$ (Morro do Côco, Sana) parece ser mais um produto de interação de uma fase fluida com a mineralogia original, com desestabilização da paragênese primária, do que uma origem por da fusão de material metassedimentar.

$\mathrm{Em}$ relação às classificações de Pitcher $(1979,1982)$, os granitos sin- $\mathrm{F}_{2}$ são comparáveis aos granitos tipo-I Cordilheirano, de composição expandida, sendo porém pouco mais evoluídos e de colocação mais profunda; os maciços $\sin -\mathrm{F}_{3}$ e $\sin -\mathrm{F}_{4}$ são mais próximos dos granitos tipo-I Caledoniano, com a maioria deles apresentando igualmente composição restrita.

A classificação com base na natureza dos enclaves, proposta por Didier et al. (1982), não é de aplicação imediata para alguns dos maciços graníticos aqui estudados. A maior parte dos maciços $\sin -\mathrm{F}_{2}$, devido à freqüência de enclaves microgranulares básicos, pode ser enquadrada nos granitos tipo-M, com exceção dos maciços Serra das Araras e Rio Turvo, que correspondem a maciços do tipo-C, ou ainda mais especificamente como subtipo-CS, destes mesmos autores. Os granitos $\sin -\mathrm{F}_{3}$ e sin- $\mathrm{F}_{4}$ são de dificil classificação, pois alguns são portadores de enclaves básicos microgranulares, enquanto em outros estes enclaves não têm sido assinalados ou são extremamente raros, ocorrendo apenas segregações e/ou agregados de máficos - ricos em biotita - do tipo schlierens, cuja origem pode estar ligada mais a processos de cristalização magmática. Assim, alguns destes maciços parecem corresponder a granitos do tipo-M, extremamente diferenciados, enquanto outros podem corresponder mais a granitos do tipo-C, possivelmente como subtipo $\mathrm{CI}$.

Considerando-se os dados geocronológicos disponiveis na literatura sobre os granitos da região do Rio de Janeiro (Cordani et al., 1968, 1973; Batista \& Kawashita, 1985; Fonseca,
1986; Menezes et al, 1987), juntamente com dados radiométricos ainda inéditos, obtidos pelo autores pelo método $\mathrm{Rb} / \mathrm{Sr}$, pode-se considerar a fase de deformação regional, $F_{2}$, com idade situada ao redor de $600-620 \mathrm{Ma}$, a fase $\mathrm{F}_{3}$ entre 560 e $530 \mathrm{e} \mathrm{F}_{4}$ ao redor de $500 \mathrm{Ma}$.

\section{SIGNIFICADO GEOTECTÔNICO E CONSIDERAÇŌES FINAIS}

O magmatismo aqui estudado teve uma duraçăo aproximada de $130 \mathrm{Ma}$, situando-se no intervalo de 490 a 620 Ma (R.Machado, dados geocronológicos inéditos). Neste sentido, o intervalo aqui discutido é mais amplo do que o intervalo proposto para o arco magmático Rio Doce por Figueiredo \& Campos Neto (1993). Assim, a idade de 590 Ma., proposta para o magmatismo précolisional do citado arco, reflete na realidade a continuidade de um processo magmático que, na região do Rio de Janeiro, teria se iniciado cerca de 30 a 40 $\mathrm{Ma}$, antes.

Finalmente, a caracterização de um magmatismo de composição expandida do tipo-I Cordilheirano (grande parte dos granitos $\sin -\mathrm{F}_{2}$ ), com afinidades cálcio-alcalina, sugere fortemente a presença de uma margem continental ativa, com subducção da litosfera oceânica, de forma análoga ao da cadeia andina. Porém, representa um nível estrutural mais profundo - as "raizes"- de um cinturão orogênico deste tipo. Os dados geoquímicos disponiveis sugerem, para a regiăo, um zoneamento magmático para os granitos sin- $\mathrm{F}_{2}$. Este zoneamento é compativel com a presença de uma zona de subducçāo mergulhando de SE para NW, neste trecho do cinturão.

O nivel crustal profundo de colocação dos granitos sin- $\mathrm{F}_{2}$ (fácies anfibolito/granulito), e o longo intervalo de tempo necessário para sua completa cristalização, favoreceram a interveniência de diversos processos de contami- 
nação e de acumulação magmática. $\mathbf{O}$ caráter harmônico do granitos $\sin -\mathrm{F}_{2}$, juntamente com a pequena diferença térmica com as rochas encaixantes, sugere, para estes magmas, uma ascensão relativamente pequena na crosta, comparada com a dos granitos $\sin -\mathrm{F}_{3}$ e sin$\mathrm{F}_{4}$.

Os granitos $\sin -\mathrm{F}_{3}$ e $\sin -\mathrm{F}_{4}$, de composição não expandida, são semelhantes aos granitos tipo-I Caledoniano, e representam os estágios tardi- a póscolisionais ( -560 a $490 \mathrm{Ma}$ ) de um magmatismo que sucedeu o evento colisional ( $-600 \mathrm{Ma}$.), durante uma orogênese Neoproterozóica.

\section{AGRADECIMENTOS}

Os autores agradecem à FAPESP (R.M. Proc. 89/3450-6), ao CNPq pela manutenção de uma bolsa de pesquisador (R.M. Proc. 300.423-62) e a um revisor anônimo pelas proveitosas sugestōes efetuadas ao trabalho.

\section{REFERÊNCIAS BIBLIOGRÁFICAS}

BAYER, P.; HORN, H; LAMMERER, B.; SCHMIDT-THOME, R.; WEBER-DIEFENBACH, K; WIEDEMANN, C.M. (1986) The Brasiliano Mobile Belt in Southern Espirito Santo (Brazil) and its igneous intrusions. Zentralblatt fïr Geologie und Palaontologie. Teil 1, v.9/10, p. 1429-1439.

BARBOSA, A.L.M.; SAD, J.H.G. (1983a) Reinterpretação das "Séries" Juiz de Fora e Paraiba, em Minas Gerais e Rio de Janeiro. In: SIMPÓSIO DE GEOLOGIA DE MINAS GERAIS, 2., Belo Horizonte, 1983. Anais. Belo Horizonte, SBG. p. 1-10. BARBOSA, A.L.M; SAD, J.H.G. (1983b) Petrologia dos charnockitos e rochas afins ao longo da divisa de Minas Gerais - Rio de Janeiro. In: SIMPÓSIO DE GEOLOGIA DE
MINAS GERAIS, 2., Belo Horizonte, 1983. Anais. Belo Horizonte, SBG. p. 63-74.

BARBOSA, A.L.M.; SAD, J.H.G. (1983c) Geoquímica e Petrologia dos charnockitos e rochas afins do Complexo Juiz de Fora, MG/RJ. In: SIMPÓSIO DE GEOLOGIA DE MINAS GERAIS, 2., Belo Horizonte, 1983. Anais. Belo Horizonte, SBG. v.3, p. $75-83$.

BARBOSA, A.L.M; SAD, J.H.G. (1985) Batólito Granitico da Serra dos Orgãos, Estado do Rio de Janeiro, Brasil: contribuição a geologia e petrologia. Boletim Especial do Núcleo de Minas Gerais, SBG. Belo Horizonte, p.49-61.

BATISTA, J.J. (1984) Caracterização dos processos geológicos evolutivos precambrianos na região de São Fidélis, norte do Estado do Rio de Janeiro. São Paulo, 123p. (Tese de Doutorado) Instituto de Geociências, Universidade de São Paulo.

BATISTA, J.J.; KAWASHITA, K. (1985) Contribuição ao acervo geocronológico da porção setentrional do cinturão Ribeira. In: SIMPÓSIO REGIONAL DE GEOLOGIA, 5., São Paulo, 1985. Atas. São Paulo, SBG. v.1, p.187-200.

BIGAZZI, G.; CORDANI, U.G.; KAWASHITA, K. (1971) Comparision between radiometric and fission trace ages of micas. Anais da Academia Brasileira de Ciências, v.43, p.663668.

BUDDINGTON, A.F. (1959) Granite emplacement with special reference to North America. American Geological Society America Bulletin, v.70, p.219-229.

CADDAH, L.F.G.; SANTOS, J.R.S.B.; VALENCCA, J.G.; PIRES, F.R.M. (1987) Granitóides da Serra da Misericórdia (R): sucessão estratigráfica, posicionamento, forma e origem. In: SIMPÓSIO DE GEOLOGIA 
REGIONAL RJ-ES, 1, Rio de Janeiro, 1987. Anais. Rio de Janeiro, SBG. p. 132-146.

CASTRO, H.O.; QUEIROZ, M.A; BARBOSA, A.L.M:; SAD, G.J.H. (1984a) Geologia das folhas Rio Preto, Valença, Barra do Piraí e Vassouras. In: CONGRESSO BRASILEIRO DE GEOLOGIA, 33., Rio de Janeiro, 1984. Anais. Rio de Janeiro, SBG. v.5, p. 2346-2354.

CASTRO, H.O; ROCHA, R.L.S.; SPERLING, E.V:; BALTAZAR, O.F. (1984b) Geologia das folhas Mangaratiba, Ilha Grande, Cunhambebe, Angra dos Reis, Rio Mambucaba/Campos de Cunha, Picinguaba e Juatinga - RJ. In: CONGRESSO BRASILEIRO DE GEOLOGIA, 33., Rio de Janeiro, 1984. Anais. Rio de Janeiro, SBG. v. 5, p. 2355-2367.

CHAPPELL, B.W.; WHITE, A.J.R. (1974) Two contrasting granite types. Pacific Geology, v.8, p.173174.

CHAPPELL, B.W.; WHITE, A.J.R. (1984) I- and S-type granite in the Lachlan Fold Belt. In: Xu-Kegin; Tu-Guangchi ( eds.): Geology of granites and their metallogenic relations, Beijing, Science Press, p.87-101.

CHAVES, M.L.S.C.; PIRES, F.R.M. (1986) Distribuição, gênese e significado econômico dos granitos dos morros da Bica e Inácio Dias, Rio de Janeiro, RJ. In: CONGRESSO BRASILEIRO DE GEOLOGLA, 34., Goiânia, 1986. Anais. Goiânia, SBG. v. 4 , p. $2879-2889$.

CORDANI, U.G.; DELHAL, J.; GOMES, C.B.; LEDENT, D. (1968) Nota preliminar sobre idades radiométricas em rochas da região da Serra do Órgãos e vizinhanças (Leste de Minas Gerais e Estado do Rio de Janeiro). Boletim da Sociedade Brasileira de Geologia, v.17, n.1, p.8992.
CORDANI, U.G.; DELHAL, J.; LEDENT, D. (1973) Orogêneses superposées dans le Pré-Cambrian du Brésil Sud-Oriental (États de Rio de Janeiro et de Minas Gerais). Revista Brasileira de Geociências, v.3, n.1, p. 1-22.

CORDANI, U.G.; TEIXEIRA, W. (1979) Comentários sobre as determinações geocronológicas existentes para as regiões das folhas Rio de Janeiro, Vitória e Iguape. In: Carta Geológica do Brasil ao Milionésimo das folhas Rio de Janeiro (SF23), Vitória (SF-24) e Iguape (SG23) - Texto Explicativo. Brasilia, DNPM. p.175-207.

DIDIER, J.; DUTHOU, J.L.; LAMEYRE, J. (1982) Mantle and crustal granites: genetic classification of orogenic granites and the natures of their enclaves. Journal of Volcanology Geothermal Research., v.14, n. 1-2, p.125-132.

FONSECA, M.J.G.; SILVA, Z.C.G; CAMPOS, D.A.; TOSATTO, P. (1979) In: Carta Geológica do Brasil ao Milionésimo, folhas Rio de Janeiro (SF-23), Vitória (SF-24) e Iguape (SG-23) - Texto Explicativo. Brasilia, DNPM, 240p.

FONSECA, A.C.; CORDANI, U.G.; KAWASHITA, K. (1984) Dados preliminares sobre a Geocronologia das rochas graniticas e suas encaixantes na cidade do Rio de JaneiroMétodo $\mathrm{Rb} / \mathrm{Sr}$. In: CONGRESSO BRASILEIRO DE GEOLOGIA, 33., Rio de Janeiro, 1984. Anais. Rio de Janeiro, SBG. v.5, p. 2333-2345.

FIGUEIREDO, M.C.H.; CAMPOS NETO, M.C. (1993) Geochemistry of the Rio Doce magmatic arc, Southeastern Brazil. Anais da Academia Brasileira de Ciências, Suplemento, v. 65, n. 1, p. $63-81$.

HIPPERT, J.F.M. (1990) Contribuição à geologia e petrologia dos "augen" gnaisses de Niterói, RJ. 
São Paulo, 203p. (Dissertação de Mestrado) Instituto de Geociências, Universidade de São Paulo

HORN, H.; WEBER-DIEFENBACH, K. (1987) Geochemical and genetic studies of three invers zoned intrusive bodiesof both alkaline and calcalkaline composition in the Ribeira Mobile Belt (Espirito Santo, Brazil). Revista Brasileira de Geociências, v. 17, n. 4, p. $488-497$

JUNHO, M.C.B. (1982) Geologia, petrografia e geoquímica preliminar do granito de Teresópolis, RJ. Rio de Janeiro, 90p. (Dissertação de Mestrado) Instituto de Geociências, Universidade Federal do Rio de Janeiro.

JUNHO, M.C.B. (1991) Contribuição à Petrologia dos maciços graníticos da Pedra Branca, Frades e Nova Friburgo, Rio de Janeiro. Rio de Janeiro, 198p. (Tese de Doutorado) Instituto de Geociências, Universidade Federal do Rio de Janeiro.

JUNHO, M.C.B. (1993) Granitóides brasilianos da região central do Estado do Rio de Janeiro - geoquímica preliminar. Anais da Academia Brasileira de Ciências, v. 65, n.2. p.161-179.

JUNHO, M.C.B.; WEBER-DIFENBACH, K; WIEDEMANN, C.; PENHA, H.M. (1987) Major and minor elements geochemistry of Pedra Branca, Frades and Nova Friburgo granitic complexes, Ribeira Mobile Belt, RJ, Brazil. Revista Brasileira de Geociências, v. 17 , n.4, p.507511.

LEONARDOS Jr, O.H. (1973) The origin and alteration of granitic rocks in Brazil: a study of metamorphism, anatexis, weathering and fertility within granitic terrains in eastern Brazil. England 183p. (PhD Thesis) University of Manchester.

MACHADO FILHO, L.; RIBEIRO,
M.W.; GONZALES, S.R.; SCHEMIMI, C.A.; SANTO NETO, A; PALMEIRA, R.C.B; PIRES, JL; TELXEIRA, W; CASTRO, H.E. (1983) Projeto RADAMBRASIL, Folhas Rio de Janeiro/Vitória (SF23/24) (Levantamento de Recursos Naturais). v.32, p.29-304.

MACHADO, R. (1983) Considerações sobre a estruturação tectônica divergente da porção ocidental do Estado do Rio de Janeiro. In: SIMPÓSIO REGIONAL DE GEOLOGIA, 4, São Paulo, 1983. Atas. São Paulo, p. 135-145.

MACHADO, R. (1990) Batólito Serra do Órgãos: uma entidade plutônica cálcio-alcalina sin-colisional de arco magmático brasiliano do cinturão Ribeira no Rio de Janeiro. In: CONGRESSO BRASILEIRO DE GEOLOGIA, 36., Natal, 1990. Boletim de Resumos. Natal, SBG. p. 221.

MACHADO, R.; PELOGGIA, A.U.G. (1987) Mapa de distribuição das rochas granitóides do Estado do Rio de Janeiro: uma avaliação preliminar das informações disponiveis. SIMPÓSIO REGIONAL DE GEOLOGIA 4., Rio Claro, 1983. Atas. Rio Claro, SBG. v.1, p.93-96.

MACHADO, R.; DEMANGE, $M$. (1991) Contexto tectônico e estrutural dos granitóides brasilianos do Estado do Rio de Janeiro. In: SIMPOSIO NACIONAL DE ESTUDOS TECTÔNICOS, 3., Rio Claro, 1991. Boletim de Resumos Expandidos. Rio Claro, SBG. p.64-65.

MACHADO, R.; DEMANGE, $M$. (1992) Granitogênese brasiliana no Estado do Rio de janeiro. Caracterização geoquímica, modelo tectônico e considerações geológica sobre o embasamento e a cobertura do cinturão Ribeira na região. In: $\mathrm{CON}$ GRESSO BRASILEIRO DE GEOLOGIA, 37., São Paulo, 1992. Boletim de Resumos Expandidos. São 
Paulo, SBG. v.1, p. 379-380.

MACHADO, R; ENDO, I. (1993) O Cinturão de Cisalhamento Atlântico: um exemplo de tectônica transpressional neoproterozóica. In: SIMPÓSIO NACIONAL DE ESTUDOS TECTÔNICOS, 4., Belo Horizonte, 1993. Anais. Belo Horizonte, SBG. p.188191.

MACHADO, R; DEMANGE, $M$. (1994) O batólito cordilherano Serra dos Orgãos: um exemplo de arco magmático brasiliano com assinatura toleítica no sistema de cisalhamento Paraiba do Sul, no Estado do Rio de Janeiro. In: CONGRESSO BRASILEIRO DE GEOLOGIA, 38., Camboriú, 1994. Boletim de Resumos Expandidos. Camboriú, SBG. v.1, p. 114-115.

MACHADO, R.; DEMANGE, M.; MONTEIRO, R.L. (1989) Granitóides do Estado do Rio de Janeiro: nivel estrutural de colocação e suas relaçōes com as fases de deformação e com o grau de metamorfismo. In: SIMPÓSIO DE GEOLOGIA DO SUDESTE, 1., Rio de Janeiro, 1989. Boletim de Resumos. Rio de Janeiro, SBG - Núcleo RJ/SP. p. 145-146.

MATOS, G.M.M.; FERRARI, P.G.; CAVAlCaNTE, J.C. (1980) Projeto Faixa Calcária Cordeiro-Cantagalo. Belo Horizonte, DNPM/ CPRM, 620p. (inédito).

MENEZES, S.O; CORDANI, U.G.; TEIXEIRA, W. (1987) Determinações geocronológicas em pegmatitos do Estado do Rio de Janeiro. In: SIMPÓSIO DE GEOLOGIA RJ-ES, 1., Rio de Janeiro, 1987. Anais. Rio de Janeiro, SBG. p. 147-165.

NUMMER, A.R; PRAZERES, M.N.; PACHECO, E.A.; ALBUQUERQUE, K.R.M.; MORAES, E.O. (1995) Transpressão e granitóides sintectônicos da região de Arrozal, oeste do Estado do Rio de Janeiro. In: SIMPÓSIO NACIONAL DE
ESTUDOS TECTÔNICOS, 5., Gramado, 1995. Boletim de Resumos Expandidos, Gramado, SBG. p. 295-207.

PENHA, H.M. (1984) Granitóides da região central do Estado do Rio de Janeiro: uma síntese dos conhecimentos existentes. In: CONGRESSO BRASILEIRO DE GEOLOGIA, 33 ., Rio de Janeiro, 1984. Anais. Rio de Janeiro, SBG. v.6, p.2849-2853.

PENHA, H.M; WIEDEMANN, C.M. (1984) Granitóides da região central do Estado do Rio de Janeiro. In: CONGRESSO BRASILEIRO DE GEOLOGIA, 33., Rio de Janeiro, 1984. Roteiro de Excursōes. Rio de Janeiro, SBG. p.5433-5456.

PENHA, H.M; FERRARI, A.L.; RIBEIRO, A; AMADOR, E.S; PENTAGNA, F.V.P.; JUNHO, M.C.B.; BRENNER, T.L, (1980) A Geologia da Folha Petrópolis. In: CONGRESSO BRASILEIRO DE GEOLOGIA, 31., Camboriú, 1980. Anais. Camboriú, SBG. v.5, p. 2965-2974.

PIRES, R.M; VALENÇA, J.G.; RIBEIRO, A (1982) Multistage generation of granite in Rio de Janeiro, Brazil. Anais da Academia Brasileira de Ciências, v. $54, \mathrm{n} .3$, p.563574.

PITCHER, W. (1979) The nature, ascent and emplacement of granite magmas. Journal of Geological Society of London, v.136, p. 627-662.

PITCHER, W. (1982) Granite type and tectonic enviroment. In: HSU, K. (ed.): Mountain building processes. London, Academic Press; p. 19-40.

PORTO Jr., R.; DUARTE, B.P.; VALENTE, S.C. (1992) Processos de diferenciação magmática atuantes na formação da fácies hololeucocrática do granito Pedra Branca, maciço da Pedra Branca, Rio de Janeiro, RJ. In: CONGRESSO BRASILEIRO DE GEOLOGIA, 38., Camboriú, 1994. Anais. Camboriú, SBG. v.6, p.2744- 
2754.

PUGET, A.J.F; PENHA, H.M. (1980) Granitos da região de Ipiranga, $\mathrm{Ma}-$ gé, RJ - considerações geoquímicas e petrológicas. In: CONGRESSO BRASILEIRO DE GEOLOGIA, 31, Camboriú, 1980. Anais. Camboriú, SBG. v. 4, p. 2215-2229.

REGO, I.T.S.F. (1989) Petrologia e geoquímica da unidade charnockitica Bela Joana, regiâo de São Fidélis, RJ. São Paulo, 348p. (Tese de Doutorado) Instituto de Geociências, Universidade de São Paulo.

REGO, I.T.S.F.; FIGUEIREDO, M.C.H. (1991) Geoquímica da unidade charnockítica Bela Joana, região de São Fidélis, Rio de Janeiro. In: CONGRESSO BRASILEIRO DE GEOQUíMICA, 3, São Paulo, 1991. Resumos. São Paulo, SBGq/Sociedade Geologica de Portugal/IG-USP, 1991. p.231-233.

REGO, I.T.S.F.; FIGUEIREDO,

M.C.H. (1994) Geoquímica da unidade Angelim, região de São Fidélis, Rio de Janeiro. In: CONGRESSO BRASILEIRO DE GEOLOGIA, 38., Camboriú, 1994. Boletim de Resumos Expandidos. Camboriú, SBG, v.3, p.153-154.

REIS, A.P.; CASTRO, H.O; DALCOMO, M.T.; FERRARI, A.L; MEL, F; NEVES, L.F.L.; VAZ, M.A.A; SILVA, V.P; NASSAR, W.M. (1982a) Geologia das Folhas Morro do Côco, Barra Seca, Itabapoama, Travessão, São João da Barra, Campos, Muçurepe, Lagoa Feia e Farol de São Tomé, RJ. In: CONGRESSO BRASILEIRO DE GEOLOGIA, 32., Salvador, 1982. Anais. Salvador, SBG. v.1, p.75-85.

REIS, A.P; ROCHA, R.L.S.; BARBOSA, A.L.M.; LIMA, E.C.V.; SAD, J.H.; ALVES, M.R.; BALTAZAR, O.F. (1982b) Geologia das Folhas Varre-Sai, Eugeonópolis, Itaperuna e Miracema, RJ. In: CONGRESSO
BRASILEIRO DE GEOLOGIA, 32. Salvador, 1982. Anais. Salvador, SBG. v.1, p.86-93.

SAD, J.H.G; BARBOSA, A.L.M (1985) A origem dos charnockitos e rochas afins da região do médio $\mathrm{Pa-}$ raiba do Sul, Estado do Rio de Janeiro. Boletim Especial do Núcleo de Minas Gerais, SBG, Belo Horizonte, p.15-27.

SAD, J.H.G.; DUTRA, C.V. (1988) Chemical compositions of supracrustal rocks from Paraíba do Sul Group, Rio de Janeiro State, Brazil. Geochimica Brasiliensis, v.2, n.2, p. 143-165.

SAD, J.H.G.; MOREIRA, M.D.; FIGUEIRAS, R.R; ARANTES, D. (1980) Projeto Carta Geológica do Estado do Rio de Janeiro. Escala 1:50.000. Folha Trajano de Morais: texto explicativo e mapa geológico. Niterói, DRM/RJ, 132p.

SIGA Jr., O.; TEIXEIRA, W; CORDANI, U.G.; KAWASHITA, K. DELHAL, J. (1982) Padrão geológico-geocronológico das rochas de alto grau da parte setentrional da Faixa Ribeira, a norte do Rio de Janeiro, Brasil. In: CONGRESSO LATINOAMERICANO DE GEOLOGIA, 5., Buenos Aires. Actas. Buenos Aires, v. 1 , p. 349-370

SPERLING, E.V;; BALTAZAR, O.F.; VIEIRA, V.S (1983) Projeto Carta Geológica do Estado do Rio de Janeiro. Folhas Mangaratiba, Itha Grande, Angra dos Reis, Rio Mambucaba, Campos de Cunha, Parati, Cunha, Picinguaba, Juatinga e Cunhanbebe. Niterói, CPRM/DRM. SV. (Relatório Final).

VALENTE, S.C.; PORTO Jr., R.; DUARTE, B.P. (1991) Geologia do Pontal de Guaratiba: implicaçōes petrogenéticas relacionadas ao batólito da Serra da Pedra Branca, Rio de Janeiro, RJ. In: SIMPÓSIO DE GEOLOGIA DO SUDESTE, 2., SP/RJ, 
São Paulo, 1991. Atas. São Paulo, SBG. p.83-90.

WIEDEMANN, C.M. (1993) The evolution of the Paleozzoic, late - to post-collisional magmatic arc of the coastal mobile belt, in the state of Espirito Santo, eastern Brazil. Anais da Academia Brasileira de Ciências, Suplemento, v. 65 , n.1, p.163-181 WIEDEMANN, C.M; PENHA, H.M; SCMIDT-THOME, R. (1987) Granitóides do Espírito Santo and Rio de Janeiro States. Revista Brasileira Geociências, v.17, n.4, p.674-689.

WIEDEMANN, C.M.; BAYER, P.; HORN, H; LAMMERER, B; LUDKA, I.P.; SCMIDT-THOME, R.; WEBER-DIEFENBACH, K. (1986) Maciços intrusivos do sul do Espírito
Santo e seu contexto regional. Revista Brasileira de Geociências, v.16, n.1, p. 24-37.

ZIMBRES, E.; KAWASHITA, K.; VAN SCHMUS, W.R. (1990) Evidências de um núcleo transamazônico na região de Cabo Frio, RJ e correlação com o Cráton da Angola. In: CONGRESSO BRASILEIRO DE GEOLOGIA, 36., Natal, 1990. Anais. Natal, SBG. v.6, p.27232743.

ZORITA, M.E.; PENHA, H.M. (1980) Geoquímica das rochas graníticas da região de Surui, Magé, RJ. In: CONGRESSO BRASILEIRO DE GEOLOGIA, 31., Camboriú, 1980. Anais. Camboriú, SBG. v.4, p.2391. 2399.

R.Machado - Instituto de Geocências, Universidade de São Paulo, Caixa Postal 11.348, CEP 05422-970, São Paulo, SP, Brasil. 